\title{
SOME CONSIDERATIONS OF URBAN DRAINAGE DESIGN PRACTICE USING EXPERIMENTAL DATA
}

\author{
Jovan Despotovic, Jasna Petrovic and Vojislav Vukmirovic \\ Faculty of Civil Engineering, University of Belgrade \\ P.O. Box 895, 11000 Belgrade, Yugoslavia
}

\begin{abstract}
Two most frequently used procedures for obtaining design flow rates in urban drainage practice are design storm approach and historical storm approach. An alternative approach is possible if a series of measured flow rates at the outlet of urban catchment is available, so the frequencies of flow rates are estimated directly. These three approaches are discussed using the measurements of rainfall and runoff at the experimental urban drainage catchment "Miljakovac" in Belgrade for the period 1981-1993.
\end{abstract}

\section{INTRODUCTION}

In rainfall-runoff modelling procedure for urban drainage design purposes one can estimate a complete runoff hydrograph, but when the flooding in the catchment is the main concern the peak flow is sufficient design variable. We shall consider only the peak flows as criteria in urban drainage systems design. The simplest approach for risk assessment in urban drainage design is to estimate return period of peak flow at defined site (e.g., see Borgman, 1963). Design flow rates are then obtained through frequency analysis of a series of observed flow rates. However, it is seldom the case that discharge is regularly and consistently observed in urban conditions. Alternatively, two most frequently used procedures for obtaining design flow rates are applied. The first approach is to establish a design storm of required frequency and to use a rainfall-runoff model to convert this design rainfall into design flow. Design storm and design flow are, in that way, assumed to have the same return period. The second approach is to perform a series of simulations with observed rainfall data ("historical rainfall") and then to obtain design flows through the frequency analysis of model outputs. In both approaches rainfall data is obtained from observations on a rain gauge station at site or from a neighbouring station.

The procedural outline of the above described three approaches for estimating design flows is presented in Fig. 1. For the sake of clarity, we shall refer to these procedures as to: 


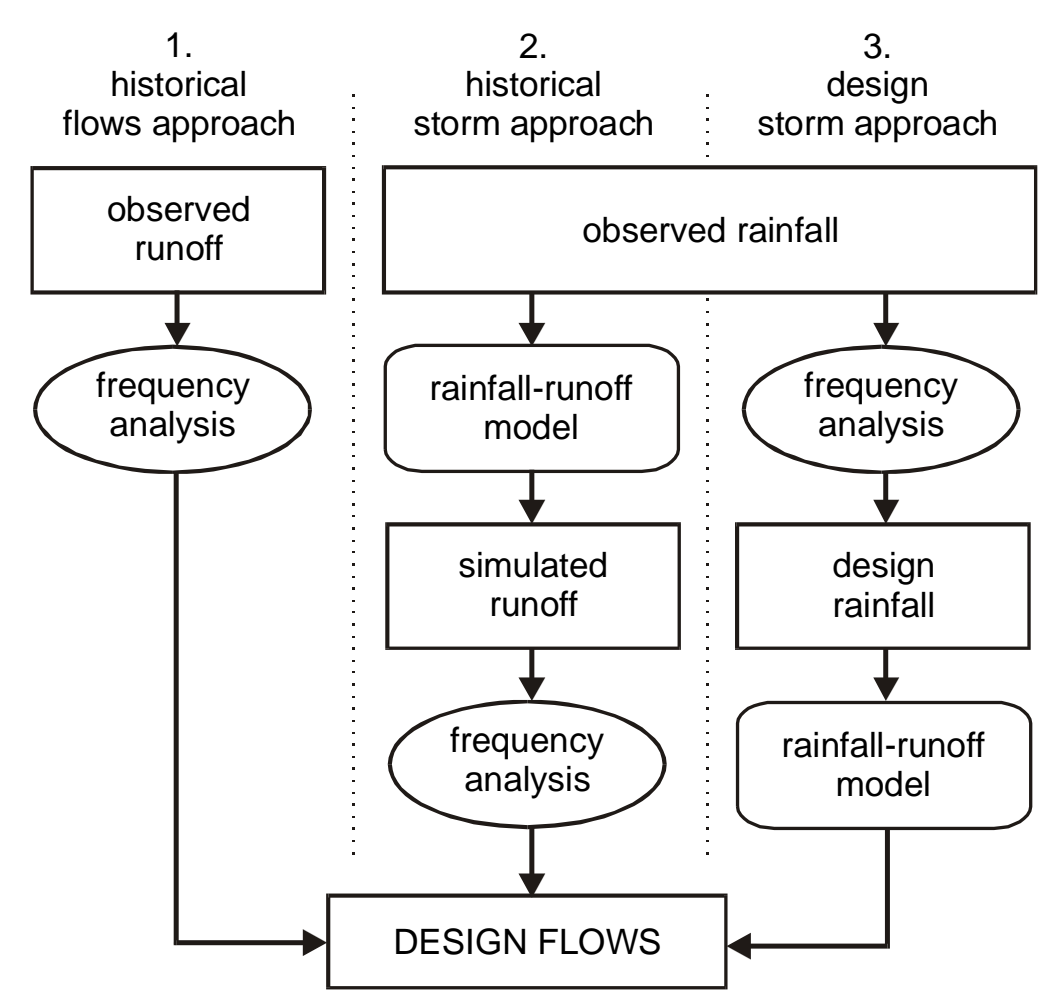

Figure 1. Outline of three procedures for estimating design flows.

1. historical flow approach - design flow obtained from frequency analysis of observed flow rates;

2. historical storm approach - design flow obtained by runoff simulation of a series of historical rainfall events;

3. design storm approach - design flow obtained with the aid of design storm of certain duration and return period.

All three approaches have advantages and disadvantages. There have been many studies related to the problem of determining more accurate flow frequencies (e.g., Packman and Kidd, 1980; Marsalek, 1984; Voorhees and Wenzel, 1984). They all agreed in several points, one being that the historical flows approach is unfeasible in the majority of cases due to the lack of measurements. Some of the studies belong to the period when computational time was an important restricting factor in choosing an approach, so they found the historical storm approach lengthy and costly, especially in case of continuous simulation models. Although today's computer technology allows any sophisticated rainfall-runoff model to be applied to any length of rainfall record, design storm concept is still appealing because of its simplicity and modest data requirements. Therefore some studies (Voorhees and Wenzel, 1984; Cao et al, 1993) were dedicated to setting up a design storm procedure which would yield design flows frequencies consistent with the true ones. Another possible approach is a compound design storm approach in which antecedent conditions are estimated using Markov renewal processes (Despotovic, 1994).

The design storm approach has been the subject of the majority of criticism. One could start with a question about plausibility of primary rainfall data processing when original data are transformed into series of rainfall depths or intensities for a range of rainfall 
durations by means of extracting the parts of original events having maximum intensity for fixed duration (Fig. 2). Moreover, choosing a proper design storm model (time pattern) and setting antecedent moisture conditions are usually arbitrary in practice. Finally, both design and historical storm approaches involve runoff simulations using a model, whose level of complexity and goodness of calibration certainly add to the overall uncertainties.

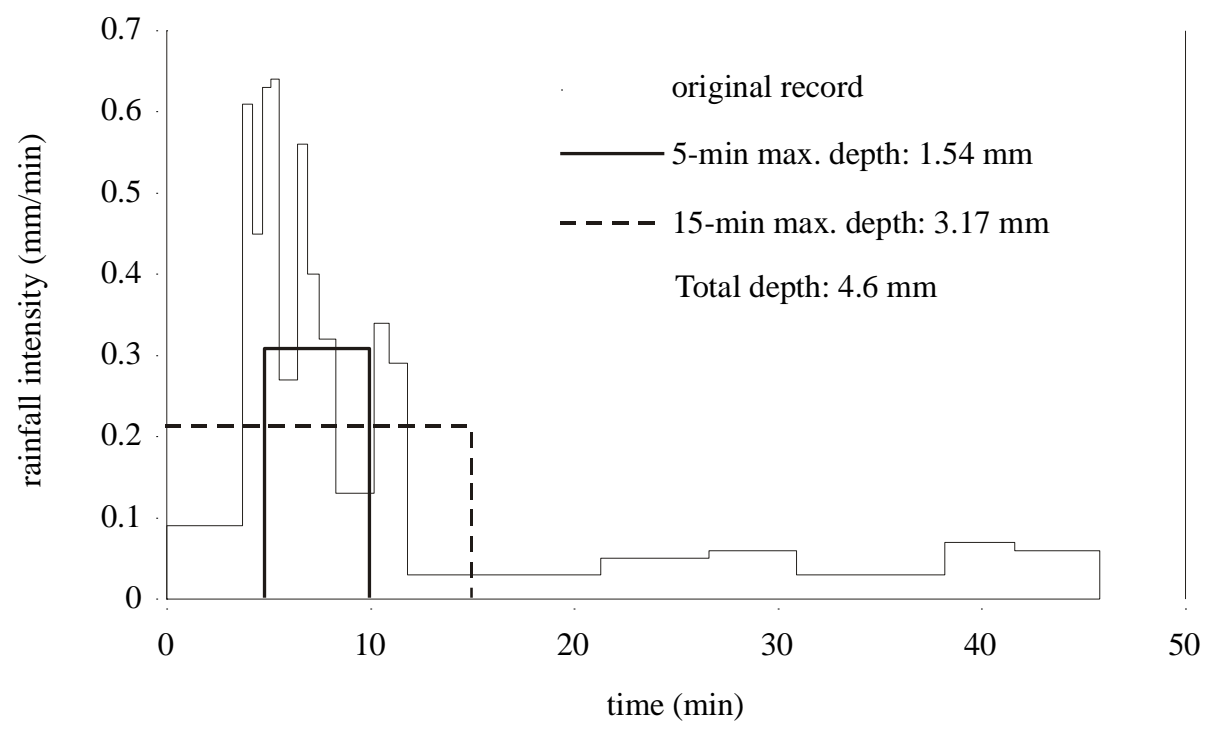

Figure 2. Illustration of the procedure for extracting maximum rainfall depths for different durations.

Away from research efforts stands the engineering practice where the block design storm and the rational formula still have a significant place. In order to make the gap between theory and practice smaller, we discuss the design flow approaches from the engineering point of view, in which the limitations in available data play a major role. These three approaches are discussed using the example of measurements of rainfall and runoff at the experimental urban drainage catchment "Miljakovac" in Belgrade for the period 19811993.

\section{EXPERIMENTAL DATA}

The experimental urban catchment "Miljakovac" (Fig. 3) was set up in early eighties in the Belgrade suburb Miljakovac 2. Only a brief description of the catchment will be presented here, and detailed description of the catchment can be found elsewhere (Maksimovic et al., 1986). The total area of the catchment is 25.5 ha and it is predominantly residential. Pervious areas are estimated at $62 \%$ of total area, and out of $38 \%$ of impervious areas, $52 \%$ is considered as effective impervious areas, i.e. about $20 \%$ of total area is effectively contributing to surface runoff. This is consistent with the average runoff coefficient calculated for all observed events, which equals $21 \%$. The catchment is rather steep, some streets having slopes up to $12 \%$. The sewer system is separate, with about 120 inlets. The south-west part of the catchment (Fig. 3) presents a very well defined subcatchment of 7.14 ha, not only by terrain characteristics, but also by a separate branch of sewer network. This fact is very useful in modelling procedure, when a model can be calibrated using subcatchment data and validated on the whole catchment. The catchment boundaries are 
well defined since they mostly follow street curbs or topographically clear watershed. Several additional inlets were constructed during the catchment set up including two grate inlets at catchment and subcatchment outlets, in order to capture all surface runoff water.

The catchment is equipped with a tipping-bucket rain gauge and two flow measuring structures. Discharge is measured at the outlets of the subcatchment and the whole catchment. Another rain gauge (Hellmann type) which is operated by the Hydrometeorological Service is located together with the tipping-bucket rain gauge, as well as a non-recording gauge used for daily totals checking. The Hellmann gauge is operational from 1981, but during the April-October season only. The tipping-bucket gauge works from 1984 and throughout year, and is also synchronized with flow measurements. An example of recorded event is presented in Fig. 4. During the 1984-1993 many rainfallrunoff events were recorded at the catchment, but also some were missed or were discarded because of poor data quality, especially during the early years. Therefore the peak flow record has some gaps, but the rainfall record is complete because of the other rain gauges.

From the engineering point of view, a reasonable doubt might exist about the length of the series (13 years) because shorter series involve greater sampling errors and therefore a more uncertain estimation of the return period. We assumed that some engineers would also consider rainfall data from the nearest rain gauge station with a sufficiently long record. In our case this is the station Vracar, located $6 \mathrm{~km}$ from the Miljakovac station, with 44 years of record.

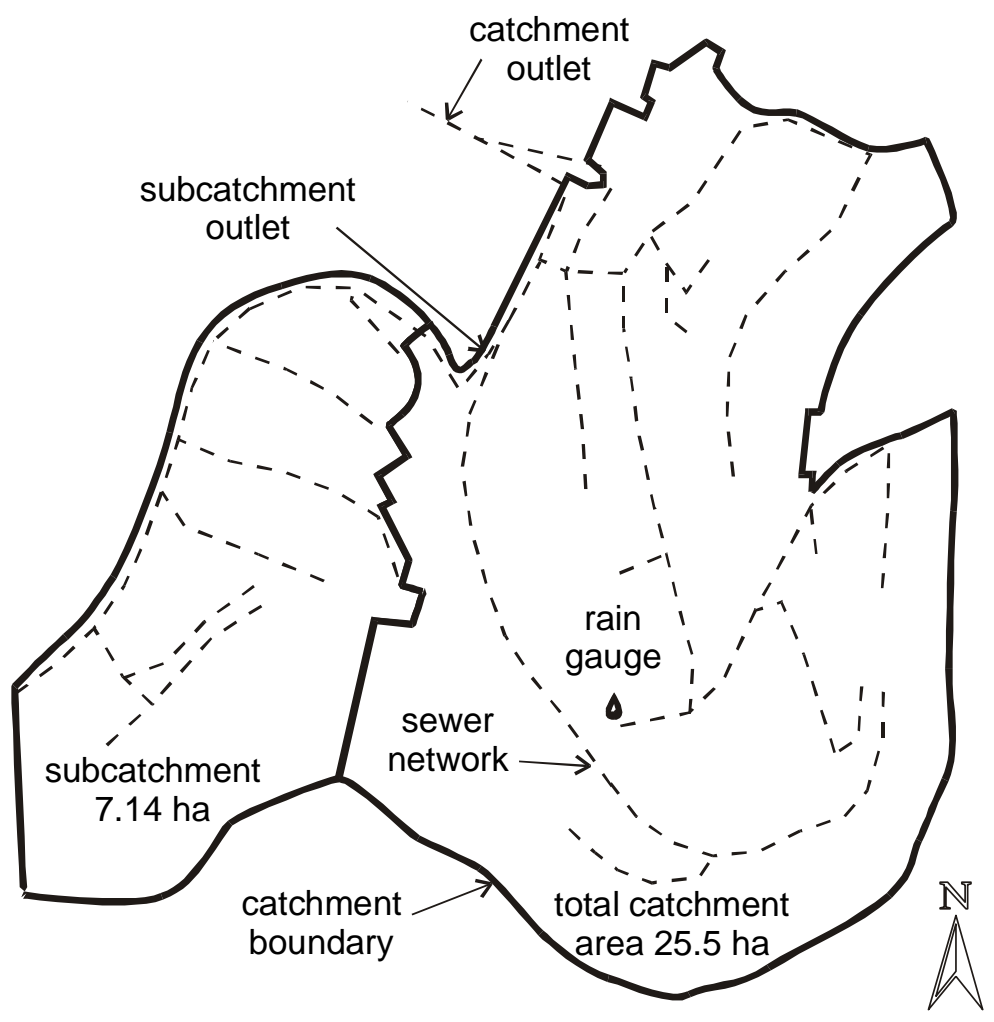

Figure 3. The layout of the experimental catchment. 


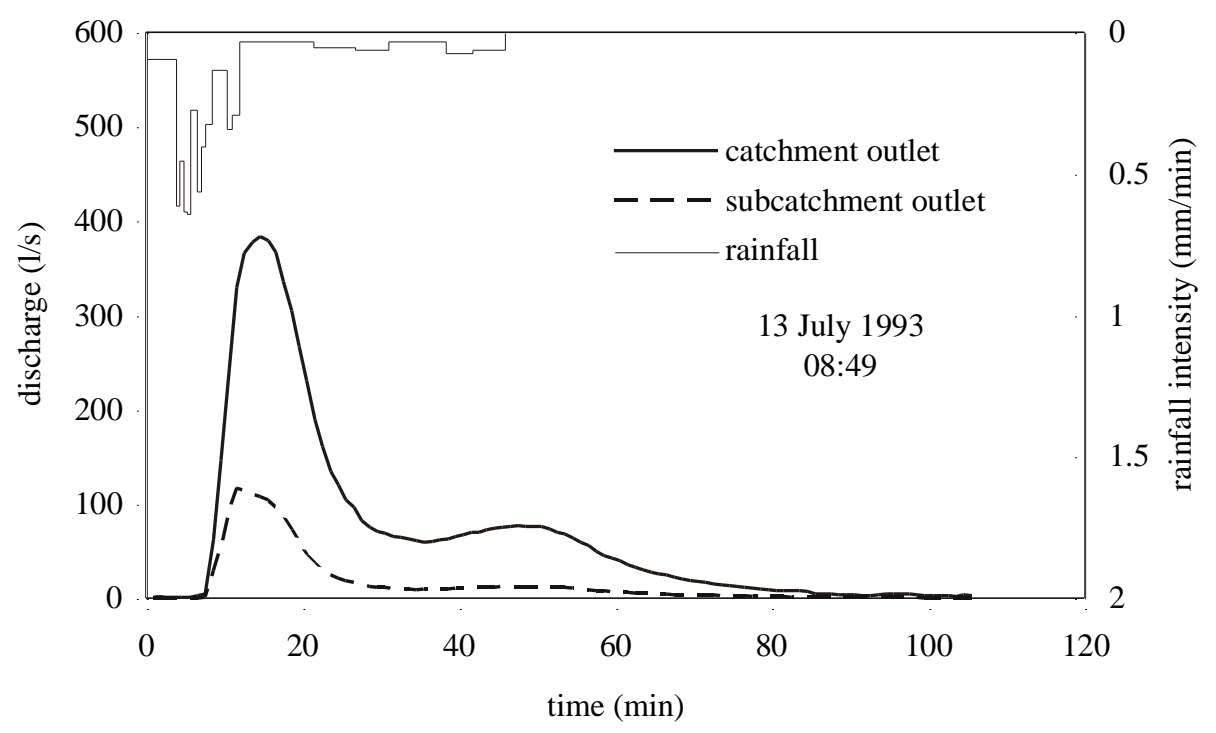

Figure 4. An example of recorded rainfall-runoff event.

\section{RAINFALL-RUNOFF SIMULATIONS}

All runoff simulations in this study were performed with the BEMUS model (IRTCUD, 1993). BEMUS is a physically based runoff model in which all major flow phases (infiltration, surface flow and sewer flow) are modelled in a simple manner, but all are based on mass and momentum conservation laws. Theoretical background of the model was described by Radojkovic and Maksimovic (1984). The model was applied to the Miljakovac data on many occasions, especially in the model testing phase. In this study we made all simulations with so called default parameters for Miljakovac, which were set during the model testing phase. Out of all reliable recorded events, a total of 50 events were selected following the criteria that peak flow was greater than $50 \mathrm{l} / \mathrm{s}$. Simulated vs. observed peak flows for these 50 events are plotted in Fig. 5. Correlation coefficient between observed and simulated peaks is 0.95 and the average value of the ratio of simulated and observed values is 1.04. Although some fine adjustment of model parameters could have improved the overall agreement between the observed and simulated peak flows, no changes were made to parameters in order to intentionally neglect the change in antecedent moisture conditions.

\section{DATA ANALYSIS}

\section{Statistical procedures}

Rainfall data analysis starts from processing of the historical rain gauge records, consisting of a series of rainfall depth increments recorded in successive time intervals. In standard rainfall processing procedure we choose a range of rainfall durations $(5,10,15,30,45,60$ minutes etc.) for which maximum rainfall depths are extracted from the record. In this way we obtain series of rainfall depths for each duration. Further processing involves choice of either annual maxima or partial duration (peaks over threshold) series. Runoff data analysis is much simpler, and it starts from extracting either annual maxima or peak over threshold 
values. We chose the annual maxima method, since it is what an engineer would choose in the majority of cases.

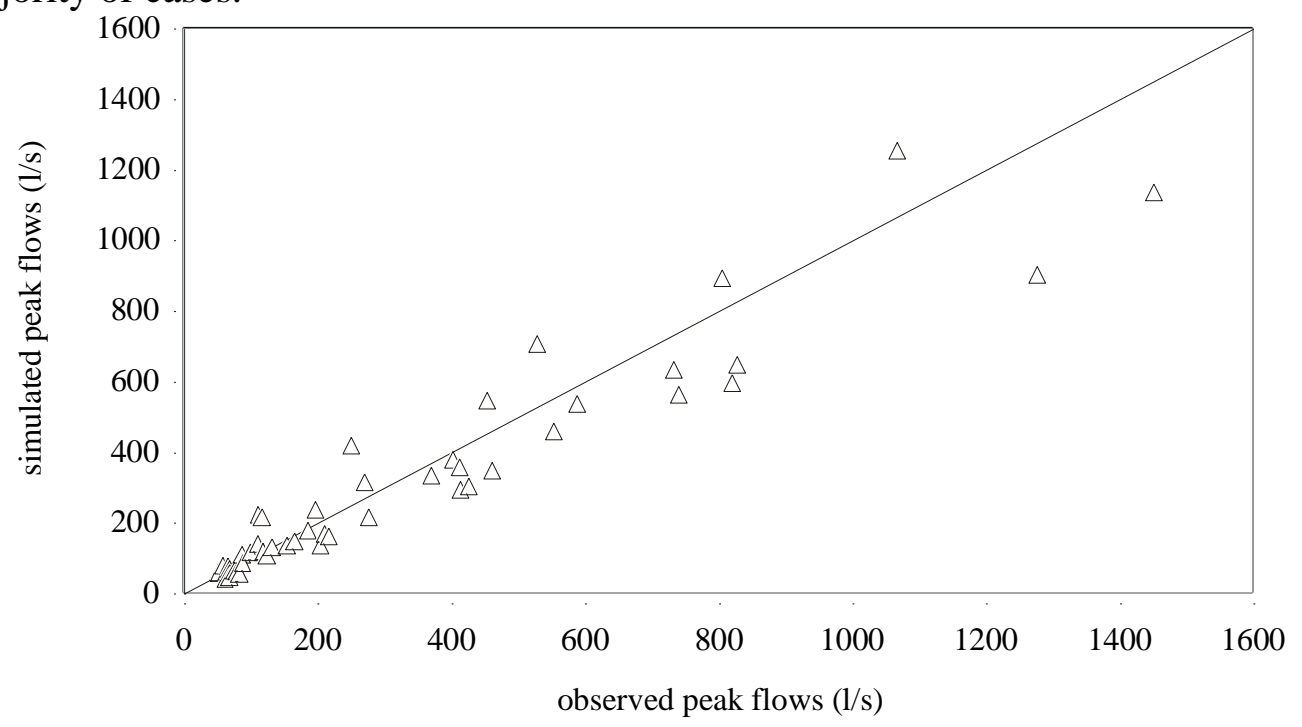

Figure 5. Observed peak flows vs. simulated with the BEMUS model.

Rainfall depth $X$ of duration $D$ is treated as a random variable with distribution function $F(x)$. Various theoretical distributions (Gumbel, Weibull, Pearson III, log normal, log Pearson III, etc.) can be fitted to the observed data. The final choice of the theoretical distribution is made on the basis of statistical tests (in our example the final choice was log Pearson III distribution). Rainfall depths with different probabilities of occurrence are then calculated using the chosen theoretical distribution. Fig. 6 presents distributions of rainfall depths for several durations for the Miljakovac station (13 years) and for the neighbouring station Vracar (44 years).

If we denote distribution function with $F(x)$, return period is defined as:

$R(x)=\frac{1}{1-F(x)}$

and it is given in years. Theoretical definition of the return period implies that rainfall depth $X_{R}$ or greater can be expected, on average, once in $R$ years. Since $0 \leq F(x) \leq 1$, return period can take values $0 \leq R(x) \leq 1$. However, because $F(x)$ can only theoretically take values 0 and 1 , in practice it is sensible to consider return period greater than 2 years and smaller than $2 N$ to $5 N$ years, where $N$ is the length of record in years. This means that for shorter records it is not recommended to extrapolate return periods beyond twice the record length.

\section{Determination of design storms}

After fitting a theoretical distribution to the series of rainfall depths for the range of durations, a relationship between rainfall duration, rainfall depth and return period 
(frequency) can be established (DDF: depth-duration-frequency). DDF curves for the Miljakovac station are given in Fig. 7.

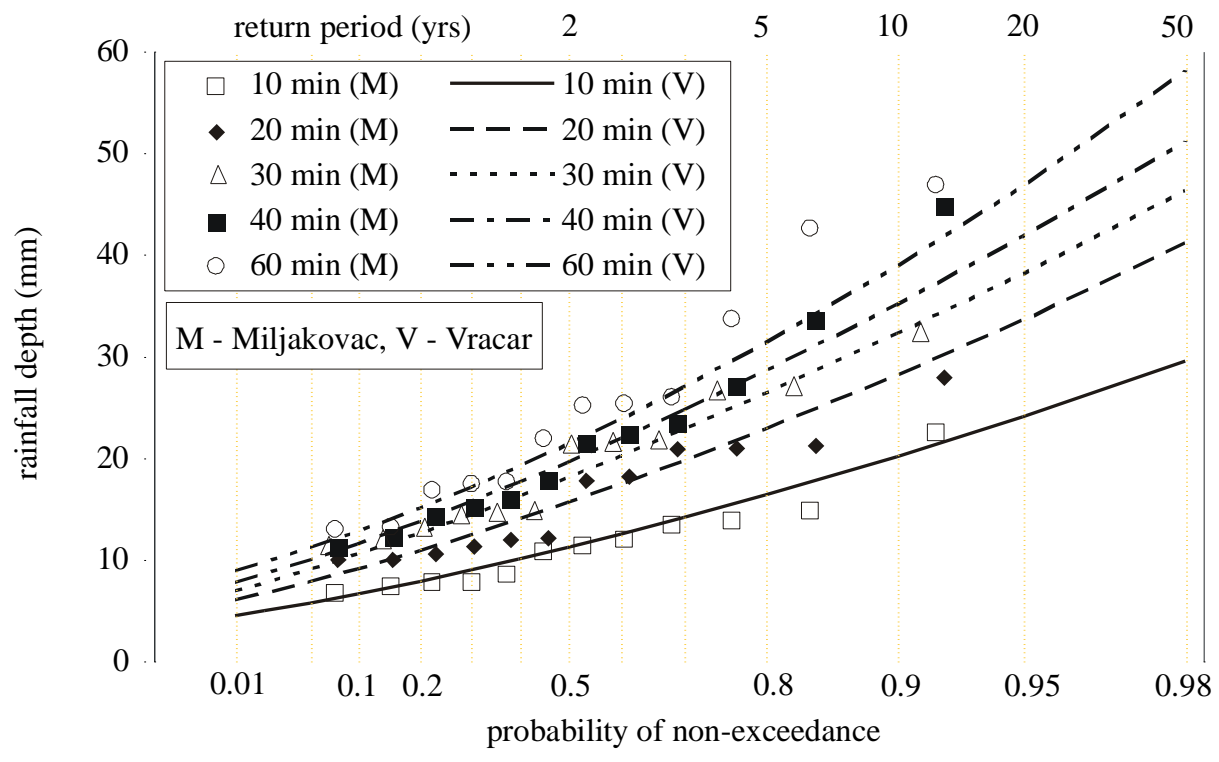

Figure 6. Distributions of rainfall depths for different durations for the Miljakovac station (points) and for the Vracar station (lines).

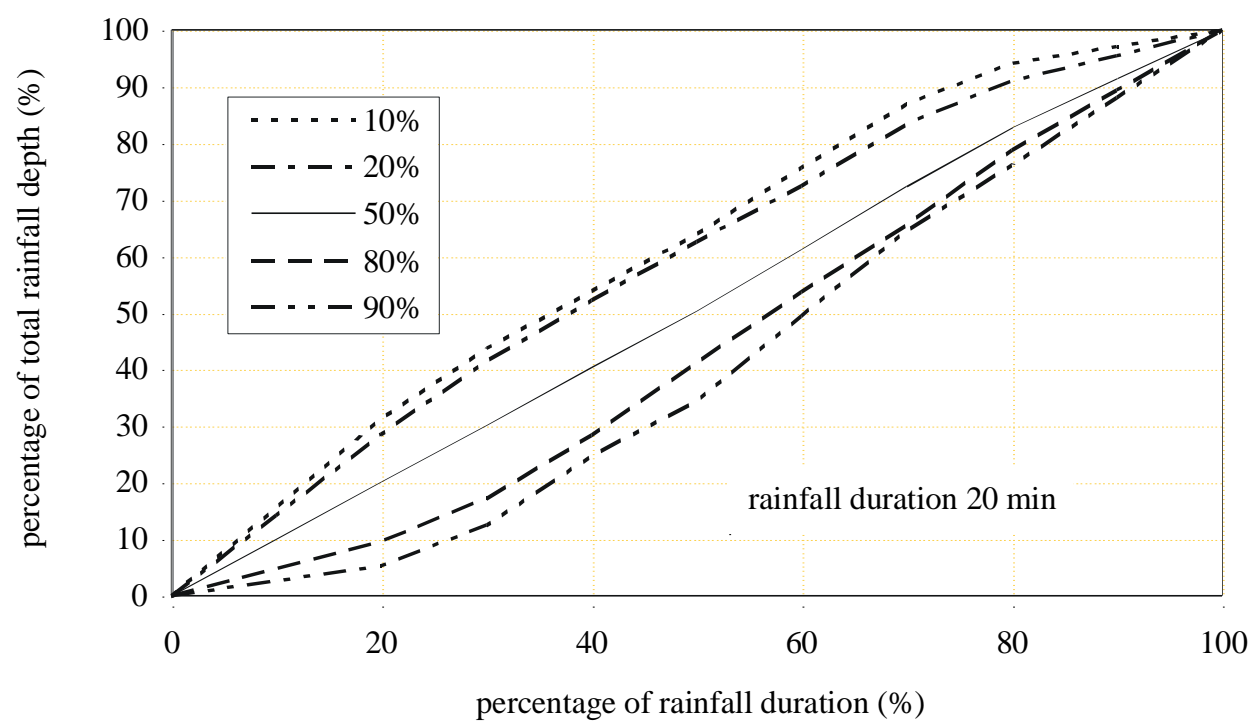

Figure 7. Depth-duration-frequency curves for Miljakovac.

Rainfall variability in time, i.e. the hyetograph shape, is analyzed here using the statistical approach (Vukmirovic and Despotovic, 1984). For each rainfall duration $D$, hyetograph shape can be presented as a two-dimensional random variable with distribution function $F(\pi, \tau)$ with dimensionless random variables $\Pi$ and $\Theta$ :

$F(\pi, \tau)=\operatorname{Pr}\{\Pi \leq \pi, \Theta \leq \tau\}$ 
where: $\Pi=X(t) / X(D)$ - ratio between rainfall depth at time $t$ and total depth after rainfall duration $D$, and $\Theta=t / D$ - dimensionless time variable. By successive calculation of distributions $F_{\tau}(\pi)=\operatorname{Pr}\{\Pi \leq \pi\}$ for a range of values of $\tau$, we can plot $\pi-\tau-F_{\tau}(\pi)$ curves representing two-dimensional distribution function and showing with which probability we can expect a certain storm pattern. An example of such dimensionless storm profiles for Miljakovac and for duration of 20 minutes is presented in Fig. 8. Combining these dimensionless curves with rainfall depth of same duration and chosen return period, design storm patterns are obtained (Fig. 9).

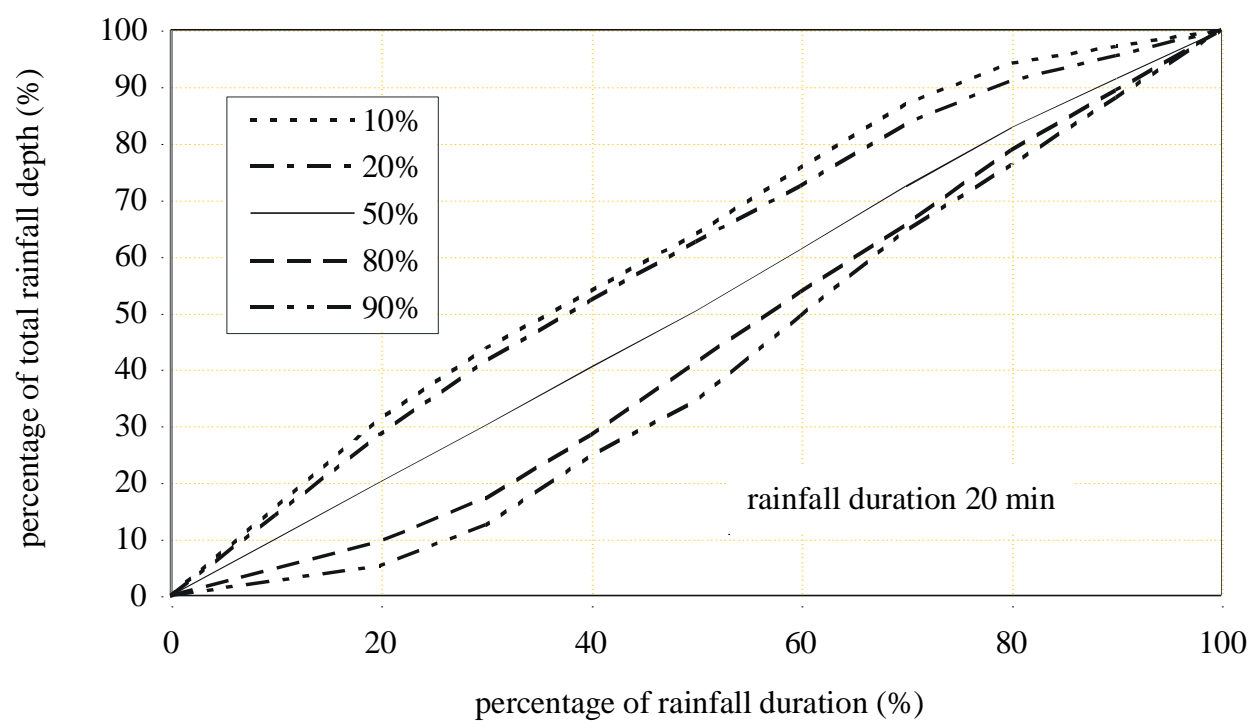

Figure 8. Dimensionless storm profiles for Miljakovac for different probabilities of occurrence.
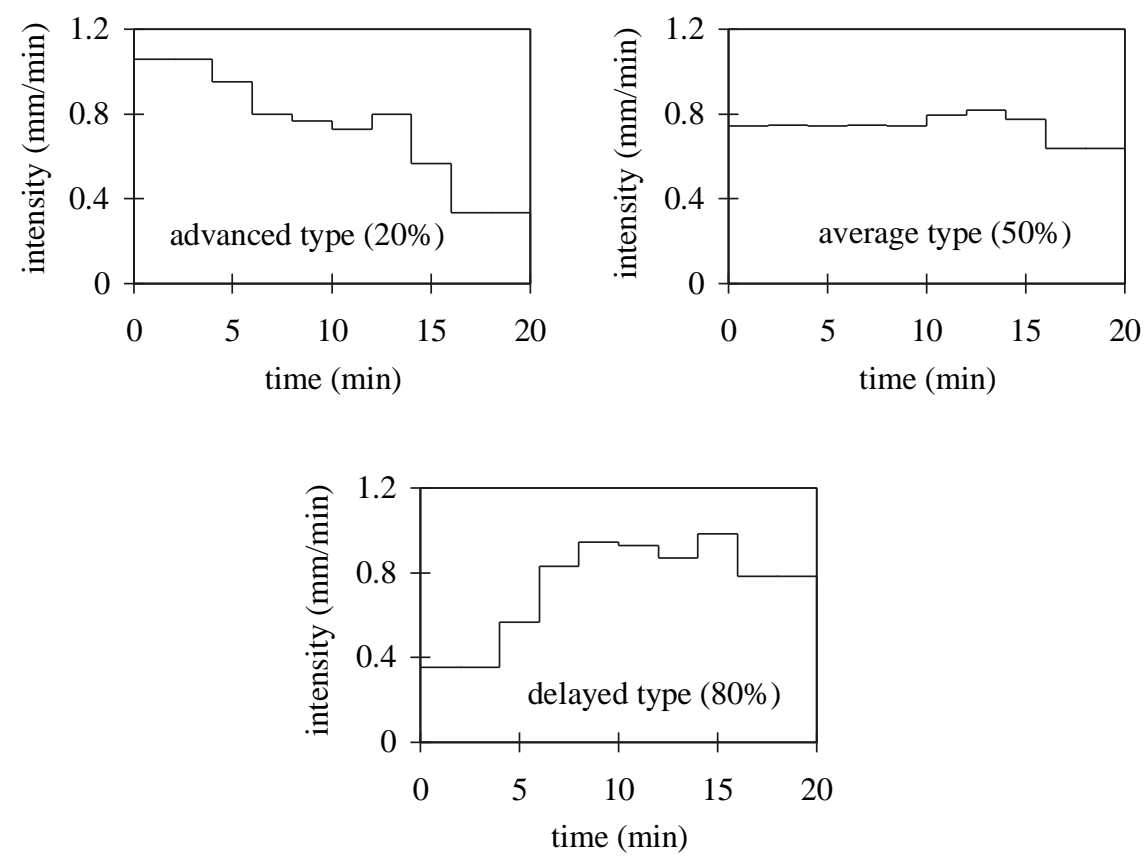
Figure 9. Design storms of 2 years return period, 20 minutes duration, and for three probabilities of occurrence.

\section{RESULTS}

Observed flow rates (historical flows)

The annual maxima series of observed flows has 10 values, covering the period 1984-1993. Probability plot for this series is given in Fig. 10. It is most likely that this probability distribution is underestimated because hydrographs of some of the extreme events were not recorded at the experimental catchment.

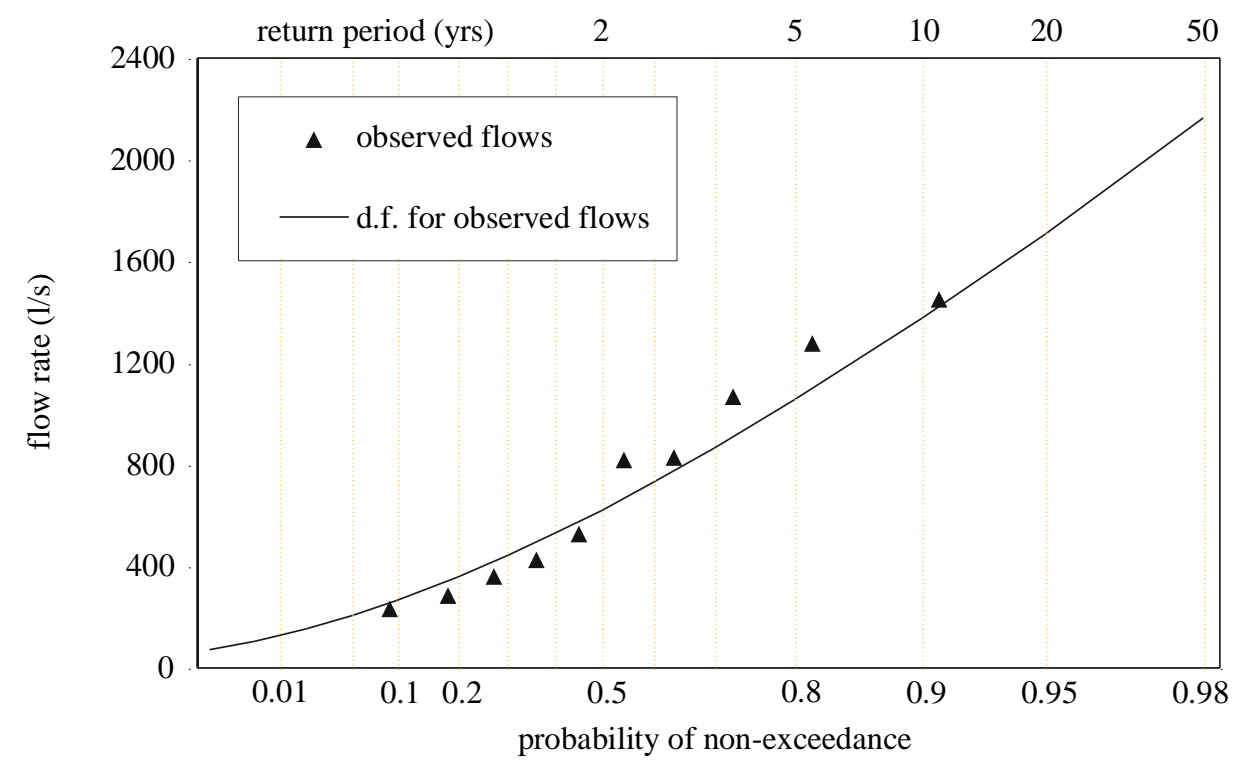

Figure 10. Probability distribution of observed peak flows.

\section{Historical rainfall}

Runoff simulations were performed for all selected extreme rainfall events which were recorded at the Miljakovac rain gauge station, as well as at the neighbouring station Vracar. From the results of all these simulations, the series of simulated annual maximum peak flows were established for frequency analysis. The length of the Miljakovac series is 13 years, and the length of the Vracar series is 44 years.

Table 1 presents the values of observed annual maximum peak flows, corresponding simulated peak flows, and simulated annual maximum peak flows at the Miljakovac station. From the table it can be seen that the model generally underestimates peak flows. The reason for this lies in default model parameters which were set for medium antecedent moisture conditions, while all annual maximum events had antecedent wet period with significant rainfall depth (Despotovic, 1994).

Figure 11 presents probability distributions of flows obtained with the "local" and "neighbour" storms, showing very little discrepancy; this was expected since the extreme 
rainfall distributions of Miljakovac and Vracar were also very similar (see Fig. 6). Comparing these distributions with the observed peak flows, it is clear that some maxima have not been recorded, what is almost never achieved at any urban experimental catchment.

Table 1. Annual maxima series for 3 different sets of peak flow values.

\begin{tabular}{|c|c|c|c|c|c|c|}
\hline \multirow[t]{2}{*}{ Year } & \multicolumn{2}{|c|}{$\begin{array}{l}\text { Observed peak flows } \\
(1 / s)\end{array}$} & \multicolumn{2}{|c|}{$\begin{array}{l}\text { Simulated peak flows - } \\
\text { corresponding to } \\
\text { observed }(1 / \mathrm{s})\end{array}$} & \multicolumn{2}{|c|}{$\begin{array}{l}\text { Simulated peak flows - } \\
\text { maximum values }(1 / \mathrm{s})\end{array}$} \\
\hline & date & value & date & value & date & value \\
\hline 1981 & & & & & 18 Jun & 588 \\
\hline 1982 & & & & & 9 Oct & 672 \\
\hline 1983 & & & & & 24 May & 1344 \\
\hline 1984 & $11 \mathrm{Aug}$ & 1066 & $11 \mathrm{Aug}$ & 1256 & $11 \mathrm{Aug}$ & 1256 \\
\hline 1985 & 1 Jun & 425 & 1 Jun & 305 & 28 Aug & 628 \\
\hline 1986 & 17 May & 1450 & 17 May & 1137 & 17 May & 1137 \\
\hline 1987 & 19 May & 819 & 19 May & 598 & 22 Jun & 4467 \\
\hline 1988 & $16 \mathrm{Jul}$ & 360 & $16 \mathrm{Jul}$ & 172 & 12 Jun & 552 \\
\hline 1989 & $1 \mathrm{Aug}$ & 285 & $1 \mathrm{Aug}$ & 189 & $28 \mathrm{Apr}$ & 1110 \\
\hline 1990 & 21 Jun & 1276 & 21 Jun & 905 & 21 Jun & 905 \\
\hline 1991 & $1 \mathrm{Oct}$ & 827 & $1 \mathrm{Oct}$ & 649 & $1 \mathrm{Oct}$ & 649 \\
\hline 1992 & 23 Apr & 232 & $23 \mathrm{Apr}$ & 335 & 25 Jun & 963 \\
\hline 1993 & $6 \mathrm{Jul}$ & 527 & $6 \mathrm{Jul}$ & 707 & $6 \mathrm{Jul}$ & 707 \\
\hline
\end{tabular}

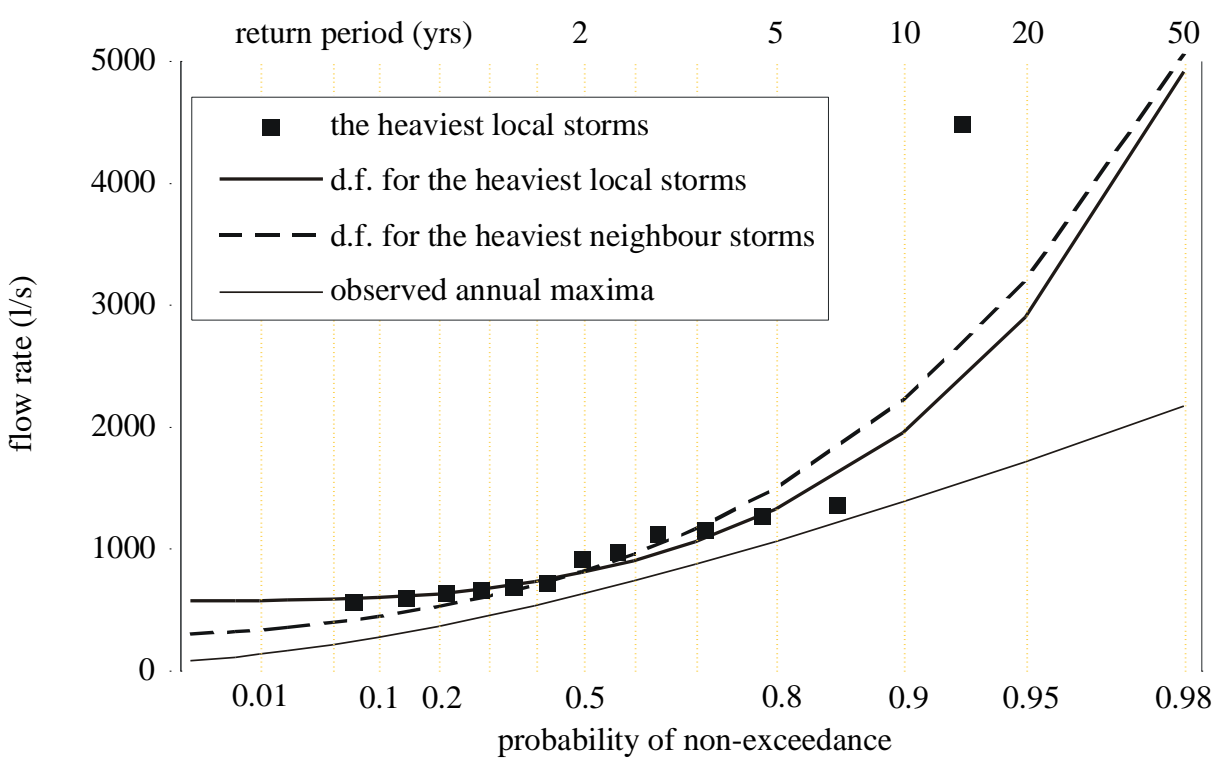

Figure 11. Probability distributions of simulated flows for two stations.

\section{Design storms}

To define design storms, the raw data from the Miljakovac station was processed using the standard extraction procedure for evaluation of the separate series for a range of rainfall 
durations. The processed data were used in frequency analysis for estimation of the DDF (depth-duration-frequency) relationship. Design storms were determined using the statistical approach, as has been described in the previous section. Durations of 10, 20 and 30 minutes were processed. All these and some block design storms were used for flow simulations. It proved that the 10-minutes storms gave the highest peak flow rates. For this reason only the results related to the 10-minutes storms are presented in Fig. 12.

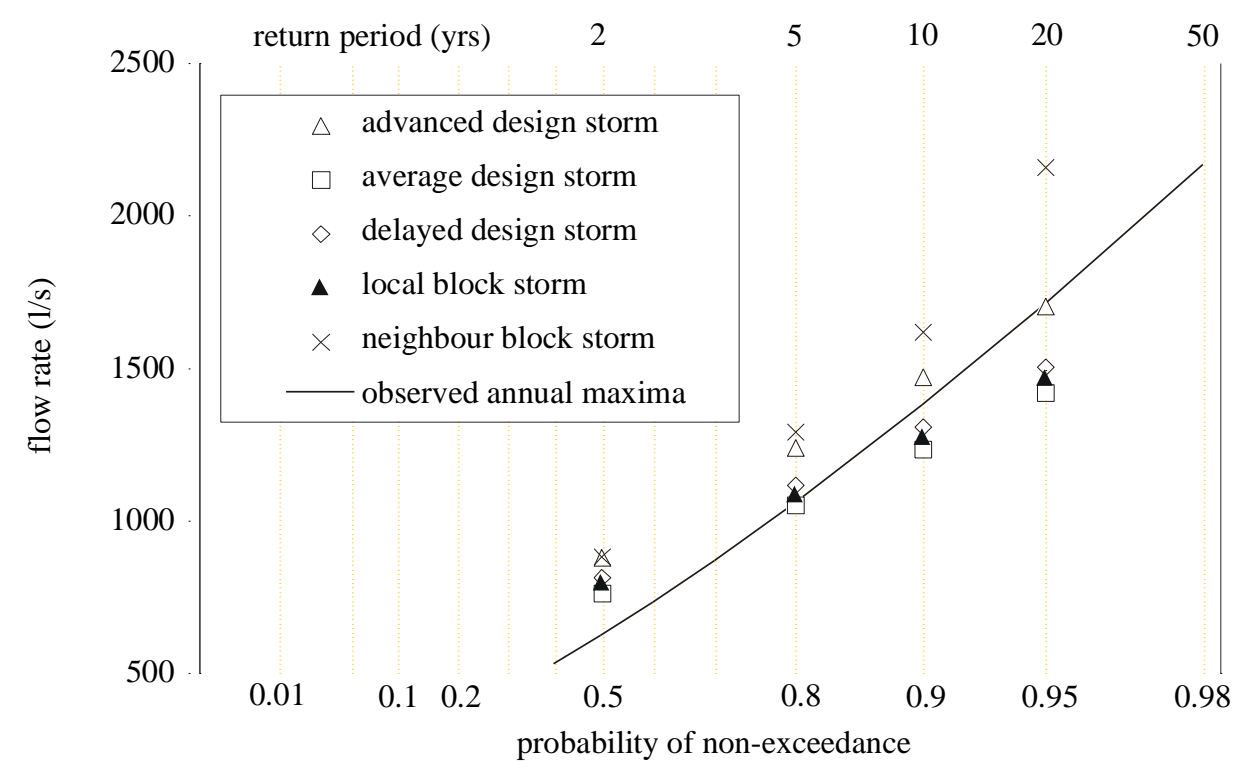

Figure 12. Flow rates simulated using design storms of 2, 5, 10 and 20 years return period.

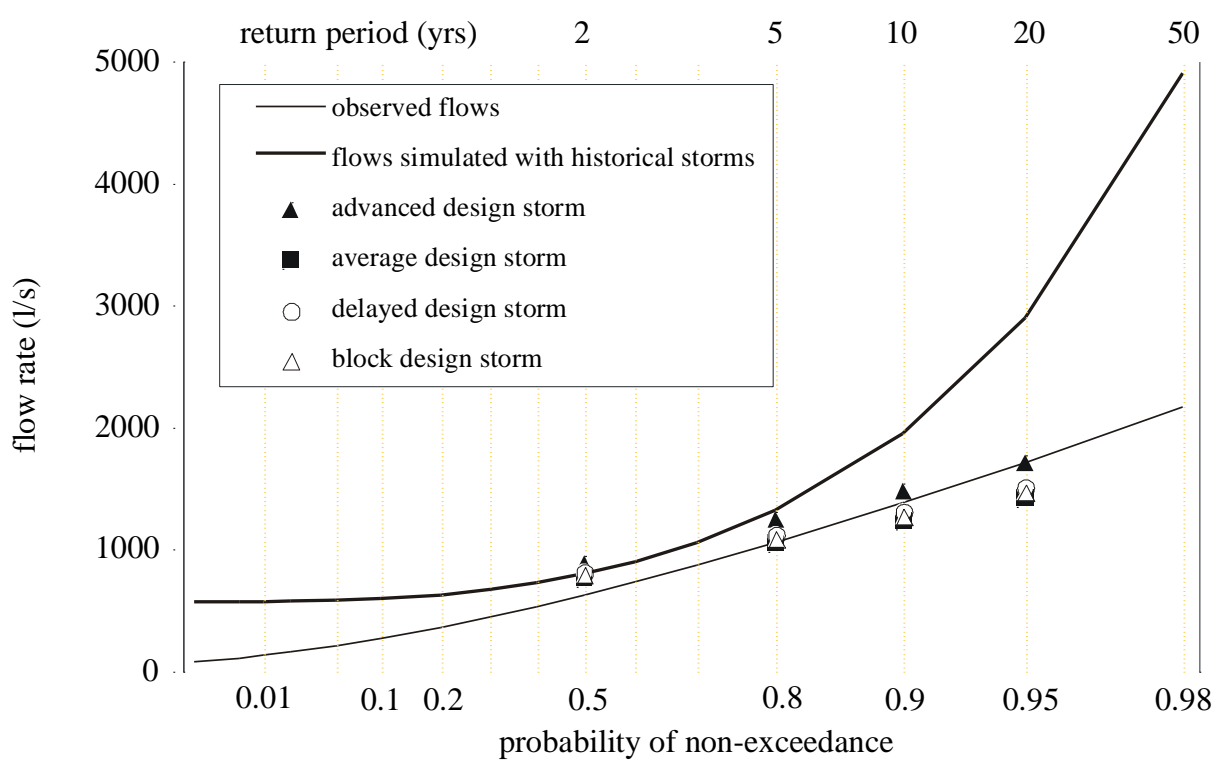

Figure 13. Summary of results of frequency analysis with different sets of data. 
Several approaches for determining design peak flows for urban drainage projects have been considered, including those present in engineering practice and some recommended by researchers:

1. design flow obtained from frequency analysis of observed flow rates (historical flow approach);

2. design flow obtained by runoff simulation of a series of historical rainfall events (historical storm approach);

3. design flow obtained with the aid of design storm of certain duration and return period (design storm approach).

Data from the urban drainage experimental catchment "Miljakovac" in Belgrade was used for analysis. The results are summarized in Fig. 13.

Although there is no doubt that the historical flows approach is the only one to produce realistic results, several almost inevitable problems are related to this approach. First of all, there is a general lack of observed discharge data at urban catchments. Even if they exist, records are short and gaps occur rather frequently due to specific problems of urban environment (pollution, vandalism). Because of this, it is very likely that the most important events would not be recorded, such as in the case of our experimental catchment. This fact is the reason for significant discrepancies between historical flows and historical storm approaches. Design storm approach, which is most frequently used in practice, proved to be closer to observed flow rates in our case, but it should be regarded with caution. From Fig. 13 it can be seen that design storms can be applied without greater risk for shorter return periods ( 2 or 5 years). Differences become significant for the 10 years return period, and even unacceptable for 20 years. Longer record at neighbouring station Vracar gives somewhat better results for design storms, but still unacceptable. Among different design storm models, block storm proved to be the worst, while any temporal variability (either advanced or delayed type of storm) produces better results.

Some other conclusions are also drawn from this study. Model calibration plays a significant role in design procedure. Our example showed that model has also to be calibrated for storms heavier than average. This is also one of the reasons why measurements should be undertaken at urban catchments under design procedure whenever possible and even for short periods, in order to record a range of events which would allow proper model calibration.

Finally, peak flow is just one of the important design variables. Other variables like runoff volumes or inter-event time which are interesting for complex systems should also be carefully analyzed. Because of their less straightforward relationship with rainfall, the sensitivity of frequencies of these variables to changes in input parameters is greater than sensitivity of peak flow frequencies.

\section{REFERENCES}

Borgman, L.E. (1963) Risk criteria, J. Waterways and Harbors Div., 89 (WW3): 1-35. 
Cao, C., Piga E. and Saba, A. (1993) Design storm calibration through continuous simulation, Proc. 6th Int. Conf. Urban Storm Drainage, Niagara Falls, Vol. I, pp. 318-323.

Despotovic, J. (1994) Random processes in precipitation analysis for assessment of direct surface flow, Ph.D. Thesis, Fac. of Civ. Eng., Univ. Belgrade.

IRTCUD (1993) BEMUS 1.11 User Manual, Int. Research and Training Center on Urban Drainage, Belgrade, Yugoslavia.

Maksimovic, C., Despotovic, J., Trisic, P. and Simic, M. (1986) Accuracy and reliability of rainfall and runoff measurements - examples, Proc. Int. Symp. on Comparison of Urban Drainage Models with Real Catchment Data, Supplements, Dubrovnik, Yugoslavia, pp. 127-133.

Marsalek, J. (1984) Urban runoff peak frequency curves, Nordic Hydrol., 15: 85-101.

Packman, J.C. and Kidd, C.H.R. (1980) A logical approach to the design storm concept, Water Resour. Res., 16 (6): 994-1000.

Radojkovic, M. and Maksimovic, C. (1984) Development, testing and application of Belgrade urban drainage model, Proc. 3rd Int. Conf. Urban Storm Drainage, Göteborg, Vol. 4, pp. 1431-1443.

Voorhees, M.L. and Wenzel, H.G. Jr. (1984) Urban design-storm sensitivity and reliability, J. Hydrol., 68: 39-60.

Vukmirovic, V. and Despotovic, J. (1984) Statistical methods of storm analysis, Wat. Sci. Tech., 16: 86-92. 